\title{
LAS FEAS SE VAN AL CIELO Y LAS BONITAS AL INFIERNO. DEBATES SOBRE LA CORPORALIDAD DE LA MUJER JOVEN EN LA IGLESIA EVANGÉLICA PENTECOSTAL DE CHILE (1927-1950)
}

\author{
Miguel ÁngEL MANSILlA*
}

\begin{abstract}
RESUMEN
Los debates referidos al cuerpo de la mujer joven pentecostal se manifiestan bajo cinco luchas dicotómicas: entre lo tradicional y lo moderno (ruralurbano e industrial-artesanal); de clase, entre la propuesta oligárquica y la popular; entre lo social y la comunitaria; de género, entre lo masculino y lo femenino; y lo generacional, entre el adulto y la joven. Sin embargo, la mujer joven se manifiesta como protagonista activa en las distintas luchas de representaciones sobre su cuerpo. Ella es la que resiste, negocia y decide entre propuestas antagónicas, y la que termina incidiendo en las innovaciones referidas al cuerpo.
\end{abstract}

PALABRAS CLAVE: MUJER, JOVEN, MUJER JOVEN, CUERPO, PENTECOSTALISMO

* Sociólogo, doctor en antropología. Investigador del INTE, Universidad Arturo Prat (UNAP), Iquique. E-Mail: mansilla.miguel@gmail.com.

Este artículo es parte de la investigación Postdoctoral Fondecyt con el proyecto «Protestantismo y pentecostalismo aymara en la Región de Tarapacá desde 1990 al 2010». N³120162. 


\title{
AS FEIAS VÃO PARA O CÉU \\ E AS BONITAS VÃO PARA O INFERNO. \\ DEBATES SOBRE A CORPORALIDADE DA MULHER JOVEM NA \\ IGREJA EVANGÉLICA PENTECOSTEL DO CHILE (1927-1950)
}

\begin{abstract}
RESUMO
Os debates sobre o corpo da mulher jovem pentecostal se manifestam sob cinco lutas dicotômicas: entre o tradicional e o moderno (rural-urbano e industrial-artesanal); de classe, entre a proposta oligárquica e a proposta popular; entre o social e o comunitário; de gênero, entre masculino e feminino; e de gerações, entre adultos e jovens. No entanto, a mulher jovem aparece como protagonista ativa nas diferentes lutas de representações sobre seu corpo. É ela que resiste, negocia e decide entre propostas conflitantes, e quem incide nas inovações relativas ao corpo.
\end{abstract}

PALAVRAS CHAVE: MULHER, JOVEM, MULHER JOVEM, CORPO, PENTECOSTALISMO

\section{THE UGLY ONES GO TO HEAVEN AND HELL BEAUTIFUL. DEBATES ON THE CORPOREALITY OF YOUNG WOMEN IN THE EVANGELICAL PENTECOSTAL CHURCH OF CHILE (1927-1950)}

\begin{abstract}
The discussions referred to the young woman's body pentecostal manifest under five fights of dichotomous: between traditional and modern (ruralurban and industrial-craft) class, between the proposed oligarchical and popular among the social and community, gender, between masculine and feminine, and generational, between adult and young. But the young woman protagonist appears as active in the various struggles of representations of the body. She is the one that resists, negotiate and decide between conflicting proposals, and ending stressing innovations relating to the body.
\end{abstract}

KEY WORDS: WOMAN, YOUNG, YOUNG WOMAN, BODY, PENTECOSTALISM 


\section{INTRODUCCIÓN}

LAS INVESTIGACIONES DEL PENTECOSTALISMO chileno fueron bastante tempranas. Antes de la década de 1950 ya encontramos algunas como Frodsham (1926), Hurtado (1941) y Caro (1942). Estas publicaciones apuntan al carácter carismático, extático y popular del pentecostalismo. No obstante, también el pentecostalismo será de interés para la literatura de la mano de Nicomedes Guzmán quien destacará dos aspectos: la fuerte discriminación que sufren los pentecostales en las calles y conventillos donde predican, así como el hecho de que, para el autor, el pentecostalismo sería parte de la diversidad del roto chileno (Guzmán, 1944).

Dado el poco espacio que tenemos, nos aventuramos a decir dos cosas. En primer lugar, se hacen estudios sobre el pentecostalismo sin pentecostales; con esto queremos decir que se habla de pentecostalismo en términos generales, pero sin destacar los sujetos. En segundo lugar, las investigaciones son de tendencia adultocéntrica. Sólo se habla de los adultos, pero nada de niños y muy poco de jóvenes. Cuando se aborda la juventud, también se hace en términos generales.

En este artículo trataremos tres temáticas poco estudiadas en referencia al pentecostalismo: el cuerpo, la juventud y la mujer joven. En primer lugar, las investigaciones de las imágenes y representaciones sobre el cuerpo en el pentecostalismo son escasas tanto en América Latina (Carozzi, 2002; Mena, 2007 y 2008; Maduro, 2007) como en Chile (Moulian, 2009; Mansilla y Llanos, 2010). Las pocas investigaciones existentes destacan que en el pentecostalismo, a pesar de la aparente polaridad entre cuerpo (soma) y espíritu (рneuma), el cuerpo adquiere una centralidad significativa en todos los ámbitos. Es considerado una residencia de lo divino y, por lo tanto, es sagrado. En este sentido, el cuerpo tiene una doble representación: es divino, porque es creación de Dios, y es instrumento, un depositario de lo sacro, un cosmos sagrado y santuario.

Por otro lado, hay escasos trabajos en castellano sobre jóvenes pentecostales o evangélicos en América Latina (Seman, 1994; Vásquez, 2007; Mansilla y Llanos, 2010; Fediakova, 2011; Mosquiera, 2010 y 2012). Tampoco hay sobre corporalidad juvenil. Pero menos aún trabajos sobre corporalidad de la mujer joven pentecostal. Para la mujer joven dicha corporalidad implica una doble complejidad: una por ser mujer religiosa y otra por ser joven. Esto se traduce en un lindar entre el deseo y el control, la vigilancia y la etiquetación 
entre lo santo y lo diabólico, lo celeste-terreno o lo infernal-terreno y lo angelical-demoníaco. El cuerpo es en sí mismo un espacio social sobrecargado de valores, pero el de la mujer joven lo es más, porque los hombres lo constituyen en un espacio de tentación para los religiosos y en un territorio de sospecha para las mujeres adultas, que ven siempre en ellas la competencia desleal. Por lo tanto, se carga sobre los cuerpos femeninos jóvenes un andamiaje difícil de cargar y soportar, pero no por ello desafiante para la joven.

Las investigaciones y publicaciones en Chile sobre la mujer joven comienzan en la década de 1980 (CEPAL, 1985). Desde los años de 1990 se han realizado varios estudios en relación a la temática (INJUV, 1997a, 1997b, 2004a, 2004b). Sin embargo, la mujer joven queda incluida, subsumida e invisibilizada en la categoría joven. Silvia Elizalde, refiriéndose a Argentina, dice que las investigaciones de la juventud se «caracterizan por una androcentrismo inferencial» (Elizalde, 2006). En Chile, las investigaciones sobre la mujer joven han tenido dificultades en la construcción del sujeto joven mujer. Esto se debe a que la dimensión de la mujer joven se reduce solo a partir de temas o problemas asociados a su sexualidad, como si ese fuese el único campo de identificación (Oyarzún, 2001). A pesar de que las publicaciones muestren esta invisibilidad u obsesión inclusiva de la mujer en la generalidad, en este caso de la juventud, no obstante los mismos jóvenes han cambiado sus representaciones sobre las jóvenes mujeres. Así lo destacan Aravena y Baeza: «los jóvenes chilenos muestran hoy una mejor disposición a reducir la distancia cognitiva hombre-mujer en un triple sentido: revisión crítica de la predominancia masculina; revalorización integral de lo femenino, y reelaboración de la igualdad de género» (Aravena y Baeza, 2010). Pero este cambio discursivo puede que esté en el plano explícito, porque en las representaciones aún pueden persistir imágenes tradicionales del ser mujer joven. Al respecto, Portocarrero señala, para el caso de Perú, que «existe un consenso en que ambos géneros deben tener iguales oportunidades. Sin embargo, en el ámbito de lo privado, el discurso patriarcal está muy presente aunque esté siendo muy criticado por los jóvenes. Las imágenes del caballero protector y galante, y de la dama, como de su casa, tienden a perder vigencia, pero aún persisten. Las jóvenes exigen que las tareas domésticas sean compartidas por los varones y aspiran a tener la misma libertad para su uso del tiempo libre» (Portocarrero, 2007).

Pero la mujer se encuentra con otro obstáculo: lo que se llama el período vital. Al respecto, Riquer y Tepichín insisten en que el perio- 
do «juventud» es más incierto para las mujeres que para los varones, por dos razones: una, porque a ellas se les sigue socializando para el matrimonio y la maternidad, como únicas posibilidades; otra, porque se mantiene la creencia de que no se requieren más que unos cuantos años de escuela para preparar a las mujeres para cumplir con su destino de género: la reproducción biológica y social de la especie (Riquer y Tepichín, 2001).

En cuanto a la visión sobre la mujer en el pentecostalismo, encontramos dos posiciones: la mujer bajo el poder patriarcal y marianista, en donde la religión pentecostal reforzaría el rol tradicional de las mujeres, a través de las prácticas y de las representaciones que son compartidas en la comunidad (Hurtado, 1993; Montecino, 2002) y una visión, si no liberadora, mejorada de la mujer con relación a otras prácticas sociales (Willems, 1967; Slootweg, 1989; Andrade, 2008; Orellana, 2009 y 2010). Sin embargo, estos trabajos no abordan el cuerpo femenino en la religión como temática. Y aún más, los trabajos sobre las mujeres en el pentecostalismo en la primera mitad del siglo XX no existen, por lo menos en Chile. Aquí estamos hablando de una época en la que todas las instituciones resaltaban los roles domésticos y materno-virginales de la mujer. Tampoco hay un abordaje de la mujer joven, ni mucho menos, desde momentos históricos poco estudiado como es desde 1927 a 1950, época en donde se inicia un fuerte proceso de modernización con sus respectivos procesos de urbanización-marginalización que tanto marcará a Chile.

La atención social que hay sobre los cuerpos femeninos jóvenes, los estudios y publicaciones en Chile sobre la mujer joven han tenido varias limitaciones. En primer lugar, la categoría de mujer joven o juventud femenina quedó relegada o implícita en el concepto indistinto de juventud. En segundo lugar, la mujer joven queda relegada también a las investigaciones sobre género, en donde joven y adulta se subsumen en el concepto de mujer. En tercer lugar, está la reducción de clase, invisibilizada en las categorías de pobre, pobladora, bajo pueblo, trabajadora u obrera. En cuarto lugar, en la categoría étnica, en donde lo indígena, india, comunidad o etnia esconde la realidad de la mujer joven. Por último, en la categoría religiosa, las investigaciones han sido muy frecuentes desde la aparición de los estudios feministas y de género, pero también la mujer joven queda subsumida. Así, aunque la mayoría de los estudios sobre juventud parten del supuesto de que esta categoría social es una construcción social, variable y cambiante, el género, como diferenciador social y cultural de la experiencia juvenil, no ha ocupado un lugar importante en las investigaciones. 
Por lo tanto, nuestro objetivo en este artículo será describir e interpretar las distintas representaciones sobre el cuerpo de la mujer joven pentecostal que manifiestan las autoridades de la Iglesia Evangélica Pentecostal. De igual modo, inferiremos de las normativas y coerciones para preguntarnos cuáles eran las posibles resistencias y decisiones que tomaban las mujeres jóvenes pentecostales sobre su cuerpo. Para ello recurriremos a la Revista Fuego Pentecostés desde el año 1927 a 1950.

\section{EL CUERPO DE LA MUJER JOVEN EN EL PENTECOSTALISMO}

La primera mitad del siglo XX, fecha en la que enmarcamos este trabajo, es una época adultocéntrica, donde el cuerpo modelo es el adulto. No importa si los cuerpos son delgados o gordos, incluso la robustez implica belleza y salud. El cuerpo del adulto pentecostal era representativo de madurez y control, santidad y consagración. A partir de esas referencias se establecen ciertos parámetros de la corporalidad para guiar a la mujer joven, obviamente con distintos matices de imposiciones, conflictos, negociaciones e innovaciones. En este trabajo destacamos cuatros aspectos: a) la belleza y la fealdad femenina; b) diseños de la corporalidad; c) fronteras corporales; d) contención corporal.

\section{a) La belleza-la fealdad femenina}

El pentecostalismo elaboró una proporcionalidad entre la fealdad física y la belleza espiritual. Lo bonito se relacionó con todo aquello que alejara la mirada de los hombres del cuerpo. Se valorará la abstracta belleza espiritual, objetivada en la oración, la lectura de la Biblia y la predicación. Los valores de una mujer se sustentaban en el proverbio N³1 de la Biblia, sobre todo el penúltimo verso que dice: «Engañosa es la gracia, y vana la hermosura: la mujer que teme a Jehová, ésa será alabada». ${ }^{1}$ La fealdad generaba confianza, mientras que la belleza era sospechosa. Incluso las imágenes del diablo eran un tanto distintas del catolicismo. El diablo no era esa imagen horrenda y espantosa, sino un ángel de luz, de belleza y encanto que ataría a los incautos hasta atraparlos, momento en que mostraba su verdadera esencia: su fealdad. El alcohol, las tabernas, la infidelidad conyugal son atractivas y encantadoras, si fueran feas y rechazables a la vista y a los deseos no serían un problema, pero una vez que el ser humano está atrapado, muestra

1 Biblia Reina Valera, versión 1909. 
su esencia maligna y fea. Por ello es que la belleza y el atractivo se relacionan con la caída y la pérdida de la libertad. Mientras que la fealdad con la confianza, la libertad y la seguridad.

Generalmente la juventud vive muy preocupada de su belleza exterior; quisiéramos ser lo mejor posible; y he oído con frecuencia que la cara es el reflejo del alma, pero he observado que no siempre guarda relación el rostro con los sentimientos íntimos. Las puras y sanas costumbres, un alma justa y delicada; un corazón recto y sensible son bellezas que renacen y se conservan nuevos perennemente. La juventud vuela llevándose todos nuestros encantos físicos que pudiéramos haber poseído y nos queda solo el recuerdo (Fuego Pentecostés $\mathrm{N}^{\circ} 99,1936: 10$ ).

En este sentido, la belleza y la fealdad no son absolutos, sino complementarios. La belleza tiene su fealdad y la fealdad tiene su belleza. Tampoco una produce la otra. No significa que la fealdad implique necesariamente una belleza espiritual. La belleza física se vincula al mundo biológico; por lo tanto, las mujeres pueden nacer bellas. En cambio, la belleza interna implica igualdad y libertad. Todas la mujeres están en las mismas condiciones y posibilidades de ser bellas a través de la regeneración del Espíritu Santo y, por lo tanto, libres de elegir serlo o no. Por otro lado, se asocia belleza física y juventud, y se destaca una proporcionalidad entre belleza física y belleza espiritual. $\mathrm{La}$ juventud más centrada en belleza física posee menor belleza espiritual. La mujer joven tiene belleza física, pero la mujer adulta tiene belleza espiritual. La belleza física se representa en la metáfora del vuelo, destacando su fugacidad, pero la belleza espiritual es perenne.

Lo perenne es un concepto muy significativo, aunque de seguro el escritor del párrafo no estaba pensando en el sentido de la diosa romana Anna Perenna (corriente perenne), de donde viene el concepto perenne. Pero sí, son interesantes los vínculos. Lo perenne tiene que ver con la permanencia y la madurez; por lo tanto, tiene que ver con la mujer adulta. Ella es la proveedora de alimentos, fundamentalmente de pasteles, en épocas en que el cocinar los escasos alimentos era un arte divino. En el mito, lo perenne es un proceso que pasa de Per annum (por año) y Anna Perenna (corriente perenne): no solo cambia de nombre, sino también de rol (Perea, 1998). La mujer joven muere en un río perseguida por los celos femeninos, pero renace en una mujer vieja, que se revela y alimenta a los hombres adultos. Este proceso de muerte y renacimiento tiene que ver con el casamiento y la maternidad. Pero también hay un cambio de la dualidad belleza-fealdad. La 
belleza física trasmuta en belleza interior, aunque ello implique feísmo, pero la belleza interior trae beneficios para la comunidad.

En el párrafo de la revista que hemos mencionado no aparece solo un control y una vigilancia sobre los cuerpos femeninos jóvenes, también hay palabras de desencanto al encanto juvenil y una desmitificación de la magia de la belleza. Esta era una época de hambre, miseria y explotación laboral. ${ }^{2}$ Por otro lado, era una época donde no había control de natalidad; por lo tanto, las mujeres podían «tener todos los hijos que Dios quisiera». Es de todos conocidos el desgaste, fundamentalmente descalificador, que produce el embarazo en el cuerpo femenino.

Por ello la recomendación no es una envidia a la belleza ni un realce del feísmo, sino una precaución, que la belleza del pobre es pasajera, mientras la fea miseria es vitalicia.

¿Cuál sería entonces la relación de las mujeres jóvenes con su cuerpo? Del texto se puede inferir que ellas tenían tres preocupaciones: belleza exterior, preocupación por su rostro y potenciar sus encantos físicos. Así, la construcción de la belleza, en este caso de la mujer joven, es una elaboración social, cultural e histórica: a) Es una elaboración social, porque es la sociedad la que define y establece los parámetros de belleza: ¿qué es la belleza femenina joven? ¿Bajo qué conceptos y definiciones generales, específicas, observables y operacionales se hacen? Pero también es una definición situada socialmente. En relación a la mujer joven pentecostal, es una mujer popular y pobre y, por lo tanto, con muy pocos recursos para invertir en su cuerpo, artificiar su belleza o mantenerla. b) Es una elaboración cultural, lo que significa que se da un conflicto entre las definiciones y parámetros de belleza entregadas por la sociedad y aquellas que la comunidad pautea, norma, prescribe y coacciona. En ese sentido, la elaboración de la belleza no sólo es conflictiva sino también negociada. Por comu-

$2 \mathrm{Al}$ respecto se pueden ver los artículos: «Cómo se vive en los conventillos de Valparaíso». En Zig-Zag. Santiago: Zig-Zag, 1905-1964. 59 v., N691 (18 mayo 1918); «Cómo vive y muere el pueblo en los conventillos». En La Mujer Nueva / boletín del Movimiento Pro-Emancipación de las Mujeres de Chile. Santiago: El Movimiento, 1935-1941 (Santiago: Gutenberg). 27 nos. Año 1, $\mathrm{N}^{\circ} 10$ (1936:6); «iNuestro pueblo tiene hambre!». En Frente Popular. Santiago: El Frente, 1936 (Santiago: Antares). 14 nos. (27 jun. 1936); «El sueño de la miseria y el hambre». En Zig-Zag. Santiago: Zig-Zag, 1905-1964. 59 v., N 1402 (1932:107-108); « Salario mínimo, salario de hambre!». En Frente Popular. Santiago: El Frente, 1936 (Santiago: Antares). 14 nos. (1936:8). 
nitario que sea un grupo religioso, las jóvenes van a la escuela, salen a la calle, van a la iglesia, van de compras o a cualquier actividad externa y se relacionan con otras concepciones de belleza que observa e integra. Pero al mismo tiempo la mujer joven necesita, requiere y se esmera en ser aceptada, valorada y deseada por su comunidad; por lo tanto, negociará su belleza entre lo que define la sociedad y norma la comunidad. c) Es un concepto histórico, tanto en el plano individual como social; individual, porque el concepto de belleza va cambiando a medida que se va cambiando de generación (niñez, juventud, adultez, vejez), y esto, a pesar de que la concepción de belleza está normada por los adultos, pero los jóvenes se resisten, se rebelan o alteran esas convenciones de belleza. No obstante, con el cambio de generación cambian los roles y, por lo tanto, también su concepto de belleza, lo que a sus vez influirá para transmitir a sus hijos o comunidad. d) En cuanto a lo histórico-social, la inserción tecnológica, los procesos urbanizadores, crisis económicas o políticas, como las guerras, también afectan al proceso construcción del concepto de belleza.

En cuanto al rostro y los encantos físicos a los cuales las mujeres jóvenes pentecostales apelaban, encontramos una lucha entre lo natural y lo artificial, lo tradicional y lo moderno, lo rural y lo urbano. El pentecostalismo de ese entonces - por lo menos hasta los años sesenta - era una religión fuertemente influida por lo campesino, lo rural, lo indígena y el mundo obrero (Willems, 1967; D’Epinay, 1968; Orellana, 2008). El lenguaje pentecostal está cargado de metáforas fáunicas, agrícolas y avícolas. Aquí una mujer bien podría ser una golondrina o una paloma que vuela o bien un árbol que renace o que es perenne. En cambio la mujer joven integra la visión de un rostro o encantos femeninos urbanos populares. En el rostro se pueden desprender miradas, silencios, lenguaje verbal, la boca, la forma de peinar o recoger el cabello. Para resaltar los encantos físicos, si las mujeres se vieran obligadas a usar faldas largas, sin escotes y sin ceñidos, ellas se encargan de incorporarle su individualidad vinculada con la fisonomía de su cuerpo, los colores y los movimientos.

No vale la pena, por lo tanto, darle mayor importancia y preocuparse de cultivar una belleza tan ficticia, sino ocuparse en conquistar las virtudes del alma, que viven y nos hacen vivir eternamente. Con nuestra belleza exterior podemos impresionar bien o agradar a las gentes; con un alma hermosa podemos agradar a Dios y a las gentes (Fuego Pentecostés $\left.\mathrm{N}^{\circ} 99,1936: 10\right)$. 
Se insiste en no aferrarse en algo tan lindo, pero fugaz, como la belleza física. Para qué gastar el dinero en afeites, perfumes, cremas y ropas nuevas, si cuando se llegue a la adultez, es decir, casarse y ser madre, a nada de eso se podrá acceder. Así, la juventud estaba asociada con la belleza, y la adultez con la fealdad física. La mujer joven es bella físicamente, pero fea espiritualmente. En cambio la mujer adulta es fea físicamente, pero bella espiritualmente. ¿En qué consiste esta belleza espiritual? En aprender a soportar el dolor: el dolor del hambre, el dolor de ver que los hijos pidan alimento y no haya qué darles, dolor ante la enfermedad y la muerte de los hijos. Eso es el horror de la fealdad. ${ }^{3}$

Dos metáforas casi imperceptibles aparecen vinculadas a ambas bellezas: la metáfora agronómica a la belleza corporal y la metáfora bélica a la belleza espiritual. La primera alude al cultivo de la belleza. Aquí se pueden desprender tres ideas sobre el cultivo del cuerpo: tierra, plantas y cultura. Lo primero aludiendo al condicionamiento geográfico y climático del cuerpo; lo segundo a la construcción cultural del cuerpo; y lo tercero a una planta como símbolo visible de los procesos estacionales en los que se representan las estaciones, referidas a la niñez, juventud y adultez o la vida y la muerte. Por otro lado, la belleza espiritual, entendida como conquista, también alude a tres dimensiones: adquisición, control y victoria. Es la idea de que la belleza espiritual no es algo acabado, sino algo en permanente adquisición. A pesar de que la belleza espiritual es indeterminada, no es algo dado sino en permanente consecución. Ambas bellezas son perdibles, pero la belleza espiritual puede ir aumentando en la medida que aumenta la edad.

¿Cuáles serían los motivos por los que habría que desplazar la belleza del cuerpo al espíritu, ir de la materialidad al simbolismo? Era

3 Esta fealdad está muy relacionada con la alta mortalidad infantil en Chile, un fenómeno que viene desde mediados del siglo XIX. Al respecto se pueden consultar los siguientes textos: Adolfo Murillo (S/F): La mortalidad en Santiago. Santiago: Cervantes. Adolfo Murillo (1896): La mortalidad urbana en Chile. Santiago: Imprenta Roma. Lucas Sierra (1895): La mortalidad de los niños en Chile. Sociedad Protectora de la Infancia. Valparaíso: Imprenta Central. Arturo Baeza (1924): «Mortalidad infantil: la falta de cultura de la madre chilena como causa predominante». En Revista de Beneficencia Pública, Vol. 14, Tomo 8, N¹. Salvador Allende (1939): «Chile tiene la más alta mortalidad infantil del mundo». La realidad médico-social chilena. Santiago: Ministerio de Salubridad, Previsión y Asistencia Social. 
porque los pentecostales pasaban mucho tiempo juntos. Con la separación del Estado de la Iglesia Católica (1925) hubo mayor libertad para predicar en las calles. La crisis de $1929,{ }^{4}$ la del carbón ${ }^{5}$ y campesina, ${ }^{6}$ atrajeron la gente al centro. Por lo tanto, paulatinamente el pentecostalismo comenzó a crecer. Las iglesias pentecostales se han caracterizado siempre por tener una mayor cantidad de mujeres que de hombres. Esto se tornaba peligroso, porque los cultos eran varias veces a la semana, mínimo de dos horas diarias, más el tiempo de compartir. Pasaban mucho tiempo en vigilias hasta altas horas de la noche. La fraternidad, carismática, hace que las personas se toquen, se besen y se abracen mucho y efusivamente. Las expresiones extáticas al interior del templo hacían que las mujeres cayeran al suelo, danzaran o pusieran las manos sobre los hombres (Kessler, 1967; Willems, 1967). Éstos y otros aspectos más contribuyeron a que las mujeres, especialmente las jóvenes, sean más controladas y vigiladas. Porque en la medida que los hombres controlan, vigilan y tapan los cuerpos jóvenes femeninos, se están controlando a sí mismos.

Hay tres ideas que sustentan el contraargumento a lo que hacen las jóvenes mujeres: ellas cultivan la belleza física, buscan impresionar físicamente y buscan agradar a sus pares. Se reiteran las metáforas agrícolas y florales asociadas a la reproducción biológica, pero también a la reproducción comunitaria. Las mujeres son «tierra fértil» donde el mensaje pentecostal es sembrado y trae frutos de conversión. Pero también son flores que polinizan el mensaje pentecostal a otras tierras. No obstante, no son «flores ni tierras» pasivas. Ellas no solo quieren ser fértiles y polinizadoras, sino también «tierras deseables»y «flores atractivas» y hacerlo lo más extensivo posible. Por lo tanto, siguiendo en el plano de la metáfora, se autocultivan. Trabajan su cuerpo, lo adornan y lo embellecen, porque ellas hacen de su cuerpo el fundamento de su identidad de género. Pero también su cuerpo es el capital con el cual pueden enfrentar la vida con mejores posibilidades: el cuerpo es un capital que fácilmente se deprecia en condiciones de pobreza; por lo tanto, hay que trabajarlo.

4 Gerardo Martínez (1983): «Causas de la gran depresión de los años treinta: aportes recientes». Revista Universitaria $\mathrm{N}^{\circ}$ 9. Santiago: PUC.

5 Ver Hernán Venegas (1993): «Crisis económica y conflictos sociales y políticos en la zona carbonífera, 1918-1931». Universitaria Nº116. Santiago: USACH.

6 José Bengoa (1990): Haciendas y campesinos. Historia social de la agricultura chilena. Tomo II. Haciendas. Santiago: Ediciones SUR. 


\section{b) Diseños de la corporalidad}

La mujer pentecostal, especialmente la mujer joven, tenía la gran oportunidad de aprender a leer en las escuelas dominicales y en las lecturas bíblicas. Uno de los criterios del espíritu pentecostal era la lectura bíblica. Quien no sabía leer debía esforzarse en aprender y tener acceso personal a la lectura bíblica; de otra manera no sería un buen o buena pentecostal. Sin embargo, pese al énfasis alfabetizador, algo esencialmente liberador en las masas empobrecidas, la lectura se circunscribía fundamentalmente a la Biblia. Los libros escolares solo se leían en la medida de la necesidad y la obligación. No era necesario o no había que perder el tiempo leyendo otros libros, por muy importantes que fuesen.

\begin{tabular}{|c|c|c|}
\hline \multicolumn{3}{|c|}{ «EL MEJOR TOCADOR DE UNA SEÑORITA» ${ }^{7}$} \\
\hline El espejo encantador. & $\begin{array}{l}\text { Conócete a ti } \\
\text { misma }\end{array}$ & $\begin{array}{c}\text { Este curioso espejo hará } \\
\text { reflejar tus faltas... }\end{array}$ \\
\hline $\begin{array}{c}\text { Loción para suavizar } \\
\text { las arrugas }\end{array}$ & Continencia. & $\begin{array}{l}\text { El uso diario de esta esencia } \\
\text { hará deshacer las arrugas... }\end{array}$ \\
\hline Pomada para los labios. & Veracidad. & $\begin{array}{c}\text { Los labios toman color de } \\
\text { carmín y despedirán aroma } \\
\text { suave... }\end{array}$ \\
\hline $\begin{array}{c}\text { Cordial para } \\
\text { dulcificar la voz. }\end{array}$ & La oración. & $\begin{array}{c}\text { Toma color de carmín } \\
\text { y despedirán aroma suave... }\end{array}$ \\
\hline Medicina para los ojos. & Compasión. & $\begin{array}{c}\text { Estas gotas darán brillo } \\
\text { a tus ojos... }\end{array}$ \\
\hline $\begin{array}{c}\text { Un incomparable par } \\
\text { de zarcillos }\end{array}$ & $\begin{array}{c}\text { Atención y } \\
\text { obediencia... }\end{array}$ & Aprenderás sabias lecciones. \\
\hline $\begin{array}{c}\text { Incomparable par de } \\
\text { brazaletes. }\end{array}$ & $\begin{array}{c}\text { Orden } \\
\text { e industria... }\end{array}$ & Tus obras darán eficiencia. \\
\hline Un cinturón elástico. & La paciencia. & $\begin{array}{c}\text { Cuanto más se usa más } \\
\text { brillante se pone... }\end{array}$ \\
\hline $\begin{array}{l}\text { Un collar de } \\
\text { riquísimas perlas. }\end{array}$ & $\begin{array}{l}\text { La resigna- } \\
\text { ción... }\end{array}$ & $\begin{array}{c}\text { Enseña a sobrellevar los } \\
\text { males de la vida. }\end{array}$ \\
\hline
\end{tabular}

Junto a la Biblia, aparecen otras lecturas como la revistas institucionales, los himnarios y libros de coros. Pero las revistas de moda están definitivamente bajo sospecha, revistas que obviamente conocían bas- 
tante bien los pastores, porque eran ellos y sólo ellos los que escribían, publicaban y dirigían las revistas Fuego Pentecostés y cualquier otra revista pentecostal que se editara en Chile. Por lo tanto, la modelación de los cuerpos femeninos jóvenes tenía un fuerte componente masculino, pero no por ello de pasividad femenina.

Hay que destacar que este decálogo al tocador que aquí aparece es muy similar al decálogo de belleza de Cavallieri (Cavallieri, 1912) para quien «una mujer que quiere ser hermosa no debe trabajar ni estudiar en exceso, para no perder su juventud y belleza» (Cavallieri, 1912:10). Obviamente la concepción de cuerpo y belleza que tenía Cavallieri era la de una joven aristocrática y oligárquica; basta con leer cada una de las recomendaciones y técnicas corporales para percatarse de ello. Mientras que la propuesta pentecostal estaba dirigida a las mujeres jóvenes, populares y pobres. Los escasos recursos apenas alcanzaban para alimentarse, debía invertirlos para cubrir el cuerpo de la manera más digna en medio de la pobreza, pero lo más higiénica posible, para mostrar un cuerpo transformado. La centralidad de los recursos debe dirigirse al estómago y no al rostro. Así que esta lucha por los decálogos de belleza, es también una lucha de clases.

En este decálogo se exponen los distintos elementos que permiten aumentar la belleza interna de la mujer joven. Lo podemos sintetizar en dos dimensiones: la subjetiva y la comunitaria. En la dimensión subjetiva: conócete a ti misma, continencia, veracidad, paciencia y resignación. En la segunda estarían la oración, la compasión, la atención-obediencia y el orden-industria.

Partiendo de una frase de la filosofía greco-clásica, se insta a la mujer a «conocerse a sí misma». Un aspecto muy interesante, considerando dos elementos de la cultura pentecostal: Uno, porque existe la creencia de la inconmensurabilidad del ser humano; otro, porque el pentecostalismo criticaba el antropocentrismo para resaltar el teocentrismo. De esta manera el ser humano solo debe concebirse como instrumento de lo divino, especialmente el cuerpo, que debería ser una vasija, un contenedor de lo sagrado. El cuerpo es un templo al que debía cuidarse, protegerse, adornarse y consagrarse y de allí el realce de los otros valores.

Sin embargo, el cuerpo también debía ser un espacio de lo comunitario, lo cual se expresaba en la oración. Había distintos tipos de oración: individual, intercesora, grupal o colectiva. Muchas personas critican la oración como un tiempo de evasión e intimismo. Empero, conociendo los distintos tipos de oraciones, éstas estaban más dedicadas a 
«ponerse en el lugar del otro», lo que implicaba adquirir conciencia y sensibilidad social. De allí la importancia de la compasión. Otro aspecto significativo es la recomendación de que la mujer adquiriera un espíritu orden-industria. Si se piensa que los pentecostales eran pobres, no solo sus viviendas, sino también el entorno de las viviendas, es decir, viviendas colindantes, así como también otros entornos, como la calle, el barrio y la población en general, lugares pobres, miserables y oscuros, a las mujeres pentecostales se les instruía en que su casa-hogar es también «casa de Dios» y que, por lo tanto, tenían que ser ordenadas, aseadas y mantenidas limpiamente (D'Epinay, 1968:170). El hogar representa el estado espiritual de la persona. Así como los hombres eran incentivados y motivados a trabajar y mantener a su familia, alejados del alcohol (Willems, 1967), las mujeres desde jóvenes eran conminadas a mantener limpias sus viviendas y las vestimentas de su cuerpo.

Esto puede parecer, a los ojos de las lecturas feministas, excesiva responsabilidad doméstica y control del cuerpo de las mujeres. Pero hay que considerar que eran épocas donde el trabajo era fundamentalmente muscular, físico; y, por lo tanto, había escasa posibilidad para que las mujeres salieran a trabajar fuera de sus casas; por otro lado, la cantidad de hijos para cuidar también se los impedía. Pero a las mujeres se les enseñaba que sus viviendas y sus cuerpos representaban la «casa de Dios», al igual que el templo, como también lo creen el protestantismo y el catolicismo. Pero al resaltar la vivienda del creyente y el cuerpo como «casa de Dios» brindaba esperanza, a pesar de la miseria del contexto geográfico, a la higiene, limpieza y orden.

Desde el punto de vista de las jóvenes, podemos reordenar el decálogo en tres dimensiones: adorno, aroma y diseño de la corporalidad. En cuanto al adorno (labios, ojos, orejas, brazos y cuello) se relaciona con el ordenamiento social, con el ajuste comunitario y la armonización entre el cuerpo que se tiene y lo que se puede arreglar. El aroma también se vincula con la metáfora arbórea donde la mujer tiene que contrarrestar el aroma natural de su cuerpo vinculado con el contexto social, la alimentación, la higiene y su biología femenina. A eso tiene que agregarle el aroma artificial. Por último está la dimensión del diseño corporal (la voz y la cintura) en donde la mujer intenta dibujar su cintura apretándose con el cinturón, marcando su figura y singularizándose con su voz.

La Biblia ruega a presentar nuestros cuerpos en sacrificio vivo, santo, agradable al Señor. Las revistas de moda ruegan a las mujeres y jóvenes 
a presentar sus cuerpos más o menos al mundo. Un cuerpo presentando al mundo no puede ser agradable a Dios. Dios no puede participar ninguna cosa con el mundo (Fuego Pentecostés $\mathrm{N}^{\circ} 12,1928: 12$ ).

Presenta dos libros en donde la mujer extrae su concepción de belleza: la Biblia y las revistas de moda. La Biblia concibe el cuerpo como templo, un espacio sagrado y consagrado. Es, pues, la Biblia el libro que debe modelar las técnicas corporales femeninas pentecostales y no las revista de modas. Mientras que las revistas de moda, dice el relato, instan a las mujeres a presentar su cuerpo para el mundo. ¿Qué significa esto? Que la mujer no debe preocuparse por adquirir la ropa que muestran las revistas, sino que ellas deben confeccionar sus propias vestimentas, pero sin que éstas sean ajustadas al cuerpo.

¿Por qué el énfasis ascético en el cuerpo joven femenino? El pentecostalismo fue, y en buena parte sigue siendo, la religión de los pobres. Christian Lalive D'Epinay le llama al pentecostalismo «iglesia de los pobres y de los miserables» (D'Epinay, 1968:177). Por lo tanto, controlar el uso de las técnicas de embellecimiento se hacía por dos motivos: uno, porque la juventud en esa época duraba muy poco, la maternidad o el casamiento era muy precoz - muy bien podía comenzar a los catorce o quince años-; por lo tanto, la juventud era un tiempo que realmente volaba o casi inexistente. Por otro lado, las niñas tenían que colaborar en su casa con los diferentes quehaceres domésticos e incluso ayudar a su madre con el cuidado de sus hermanos pequeños. Pero en el pentecostalismo, tanto hombres como mujeres, la asistencia a los cultos había que hacerlo con ropa limpia o con la mejor ropa que hubiese. El cambio de vida había que mostrarlo con el cambio en la forma de vestir. Por lo tanto, se incentivaba a las mujeres jóvenes a focalizar e invertir los escasos recursos económicos en lo útil y necesario considerado por la comunidad pentecostal: alimentación y vestimenta.

Las jóvenes se resisten y pretenden, junto a la Biblia, que las revistas de modas sean las que les orienten a cómo administrar su cuerpo. Los pentecostales asocian el cuerpo a los templos: algo sagrado. Pero también vinculados a la sacralidad protestante (herencia pentecostal) donde hay un templo-cuerpo sin adornos. De igual forma, el cuerpo femenino debía ser sin adornos, de sencillez ascética y tapado, que no sea la estética arquitectónica la que atraiga sino lo ética teológica: no la forma sino el contenido. No obstante, las jóvenes luchan para no equiparar su cuerpo al templo sino más bien una casa. Es decir, un cuerpo al cual mostrar, presentar y exponer. 


\section{c) Fronteras corporales}

La idea era definir de manera delimitada y clara que la construcción corporal femenina debe estar definida y antecedida externamente por la diferenciación social y cultural del género, por aquello que la comunidad pentecostal define externamente por lo femenino: cabello largo, faldas largas y rostro sin maquillaje.

Una manera de vestir que presenta el cuerpo al mundo es un vestuario mundano, un cuerpo que viste un vestuario mundano es un cuerpo mundano. Un cuerpo mundano no puede ser aceptado por Dios, ni ser transformado por Cristo, ni vestir el vestido de boda que Cristo dará al cuerpo transformado (Fuego Pentecostés $\mathrm{N}^{\circ} 12,1928: 12$ ).

Cuerpo mundano versus cuerpo transformado. Aquí se destaca algo que es muy característico de la cultura pentecostal: la creencia milenial, en el sentido del regreso de Cristo a buscar a su pueblo para redimirlo de su miseria y pobreza. Se destaca una segunda metáfora que tiene que ver con la asimilación de la iglesia a un cuerpo de novia, es decir, juventud, vitalidad y fertilidad, algo que se asemeja mucho al pentecostalismo del siglo XX, en América Latina, cuya función principal de expansión y crecimiento se debe al rol de la mujer. Pero las representaciones de cuerpo mundano y vestimenta mundana son bastante ambiguas para saber de qué tipo de cuerpo o vestimenta se trata. Solo se puede entender en el contexto de la comunidad de ese entonces. Pero sí se puede desprender que los consejos estaban remitidos a que las mujeres no compraran la ropa, sino que la hicieran con sus propias manos e imaginación.

¿Vestuario mundano y cuerpo mundano? ¿Vestido de boda? Cuesta entender en el párrafo a qué se refiere, pero se puede inferir por la época lo que podría significar aquello: ropa escotada, vestidos ceñidos al cuerpo, vestidos que permitieran mostrar las piernas. El vestido de boda hace referencia a la concepción de la iglesia pentecostal como una mujer joven y virgen que está esperando casarse con el Mesías en el premilenio.

Las mujeres cristianas tendrán que escoger entre Cristo y el mundo. Si eligen de agradar al mundo no pueden agradar a Cristo, y si eligen agradar a Cristo no pueden agradar al mundo (Fuego Pentecostés $\mathrm{N}^{\circ} 12$, 1928:12). 
A la mujer se le presentan dos representaciones masculinas opuestas: Cristo o el mundo. Hay que elegir entre ser una mujer del mundo o la mujer de Cristo. Un cuerpo para el mundo o un cuerpo para Cristo. Un cuerpo tapado o un cuerpo exhibido, un cuerpo sobrio o un cuerpo cuyas vestimentas evidencian las curvaturas femeninas.

La identidad femenina como identidad de género se elabora a partir de la referencia con el otro, en este caso con el hombre. Por ello se le insta a la mujer a elegir entre dos símbolos masculinos: el mundo o Cristo. Las jóvenes pentecostales no buscan las oposiciones sino la integración. Se resalta varias veces cómo las jóvenes buscan agradar al mundo, referido a que el pentecostalismo tenía como norma enfatizar el matrimonio intragámico; en cambio, las mujeres eligen casarse con hombres fuera del pentecostalismo. Lo otro es que las mujeres en vez de buscar agradar a Cristo, buscan agradar a los hombres. Se visten y coquetean, se dejan cortejar, algo considerado como mundano.

La palabra de Dios nos enseña que es abominable que el hombre se vista de mujer y la mujer se vista de hombre, esta enseñanza es de Moisés, y el gran apóstol Pablo, dice «que es vergonzoso a la mujer cortarse el cabello o raparse; y dice la naturaleza misma, ¿no os enseña que al varón le es deshonroso dejarse crecer el cabello? (Fuego Pentecostés $\mathrm{N}^{\circ} 12,1928: 12$ ).

Otro aspecto significativo es la idea de diferenciar constantemente el cuerpo femenino del cuerpo masculino, por la diferencia en el tipo de vestimentas: faldas para las mujeres y pantalones para los hombres. Un segundo aspecto es el uso del cabello: pelo largo para las mujeres y pelo corto para los hombres. El uso de pantalones y el cabello corto en las mujeres implican una masculinización y es considerado como un acto de rebeldía, peor aún, de abominación, lo que en un contexto religioso está vinculado al tabú, es decir, a la impureza ritual. Pero en el pentecostalismo la impureza ritual se puede entender como que una mujer vestida de manera impertinente no podría participar de los ritos religiosos.

¿Por qué el énfasis en las tipologías corporales? El crecimiento del pentecostalismo lo presentaba como alternativa religiosa, ${ }^{8} \mathrm{y}$, por lo tanto, respondía a las preguntas: ¿quiénes somos?, ¿qué somos?, ¿cómo

8 A fines de la década de 1930 el pentecostalismo ya era visible y su crecimiento notorio que atrajo la atención de sacerdotes católicos. Alberto Hurtado (1941) y José María Caro (1942). 
nos identifican? (Hoover, 1948). Estas preguntas se responden no sólo desde la perspectiva del nosotros, sino también en oposición a los demás. Las mujeres, y también los hombres, debían identificarse y ser identificados antes que todo por su forma de vestir, como primera aproximación a la corporalidad. Ante la pobreza, vestir digna e higiénicamente era símbolo tanto de belleza como de estatus.

Las mujeres comenzaron a usar pantalones a fines del siglo XIX en el contexto del mundo fabril y obrero. Es posible que el ingreso de la mujer popular al mundo laboral fabril incluya el uso de pantalones, aunque aquello no se debe sólo a la necesidad del contexto laboral, sino también a la protesta contra lo religioso y patriarcal. El uso del pantalón se veía peligroso, porque la mujer exponía su figura corporal más acentuada, pero también se veía peligroso por su veta masculinizadora.

\section{d) Contención corporal}

El control y la vigilancia sobre los cuerpos femeninos se debían fundamentar no solo en consejos y sugerencias, sino en miedos metafísicos para tener una mayor eficacia simbólica. Si la pobreza, ya era un infierno para los pobres, cuanto más un infierno eterno.

Yo estaba observándolo todo; enseguida entraron en fila todas las señoritas de la Escuela Bíblica de Glad Tidings, una por una; y cuando Jesús nos vio, no hubo ni una sonrisa ni un movimiento en su rostro. Él nos indicó que pasásemos a su derecha y allí nos pasamos formando un semicírculo, y esperamos. Después de un rato, por el pasillo de en medio entraron veintiuna muchachas, todas polveadas y pintadas, con el cabello recortado, faldas cortas y medias de seda transparente. Todas se pararon en rededor de la silla del juez como esperando su sentencia. Jesús las vio y dijo: «Con vuestro polvo y pintura y con la exposición de vuestra carne habéis arrastrado hombres al infierno. Id a encontrarlos allá (Fuego Pentecostés $\mathrm{N}^{\circ} 12,1928: 12$ ).

Un aspecto notorio de esta cita es que el relato es extraído de una revista protestante norteamericana. Lo segundo es que en esta fecha quien dirigía la revista era Willis Hoover, quien era conocedor del inglés para traducir. Aquí se destaca que las mujeres afeadas se van al cielo, a la derecha, mientras que las bonitas o embellecidas se van al infierno.

¿Qué características presentan estas jóvenes que se van al infierno? Estas jóvenes usan el cabello corto, bisuterías, faldas cortas (no minifaldas, un fenómeno de la década de 1960) y medías transparentes. Es 
decir, jóvenes que invierten en su belleza, y en vez de hacerse ellas mismas sus vestimentas, prefieren comprar sus ropas. Junto a la condena de la sensualidad somática y la belleza física aparecen dos ideas implícitas: La primera es una concepción de la mujer que gira entre la autonomía y la culpabilidad social. Y es también una lucha entre las técnicas del cuerpo artesanal y el cuerpo industrializado, entre las técnicas corporales campesinas y rurales y las técnicas corporales urbanas. Por lo tanto, lo primero se asimila al cielo y lo segundo al infierno.

La segunda idea es un crítica y una lucha para que la mujer sea un ser autónomo, que no se vista para el hombre sino para ella. Pero esta idea liberadora se ve borrada por hacer a la mujer responsable de la condición descarriada del hombre. Finalmente ésta es la idea fuerza que permanece: la mujer siempre es culpable por su belleza y atractivos físicos, que atrae a los hombres, los hacen caer y los conducen al infierno. Se termina resaltando la idea de la «mujer trampa», la que hace caer al hombre.

Este tipo de mujeres jóvenes que aparecen aquí pertenecen más bien al contexto norteamericano, sobre todo por el uso de faldas cortas (que no tapara el zapato) y el uso de medias de seda. Es decir, muy difícil en un contexto de pobreza, aunque sí las mujeres jóvenes aristocráticas chilenas las usaban. Por lo tanto, es una lucha de clases entre mujeres jóvenes de clase alta y mujeres jóvenes pobres. Por otro lado, sí es más probable el uso de polvos, pinturas y el cabello más corto, como una forma de manifestar mayor independencia.

enseguida tomaron ceniza ardiendo y las ponían en sus caras en lugar de polvo; y luego brasas vivas en los labios y las mejillas para pintarlas. ¡Oh! cómo chillaban y gritaban aquellas muchachas... llegamos al lago de fuego... el ángel negro mandó a las muchachas que pasaran por encima de estas cañerías y tuvieron que hacerlo. Con el menor movimiento falso, o con la más leve vuelta tendrían que caer en el fuego... Abajo podían verse las cabezas de hombres flotando en el fuego líquido. El ángel dijo a las muchachas: «vosotras habéis anhelado la admiración de estos hombres. La tendréis por toda la eternidad» (Fuego Pentecostés $\mathrm{N}^{\circ} 12,1928: 12$ ).

Se manifiesta que el infierno es el reverso de la tierra. En este relato las especias y afeites femeninos y los deseos de ser bellas y deseadas aparecen como instrumentos de tortura. La idea era desincentivar la centralidad de la belleza física con la imaginería infernal. 
Por lo tanto, si no resulta la normativa o el consejo, estaba la coerción simbólica del infierno, creencia muy fuerte en ese entonces en todos los grupos religiosos. Por ello, las mujeres jóvenes no deberían buscar agradar a los hombres con su forma de vestir.

Jesús volvió a mí y me dijo: «AHORA, HIJA, ¿CONTINUARÁS TÚ USANDO POLVO Y CREMA?». Le contesté: «NO, SEÑOR, NUNCA, NUNCA». Entonces se volvió a las muchachas y les dijo: «APRENDED LA LECCIÓN». ${ }^{9}$

Este relato es una de las formas de control y vigilancia sobre la corporalidad femenina. Es un sermón donde la letra entra con fuego. Es la forma de socializar y enseñar la parsimonia y la parquedad somática a extremo.

Algunas madres estaban ricamente vestidas y casi todas traían joyas. Cuando llegaban cerca de Jesús exclamaban: ¿Dónde están nuestras hijas? ¿Dónde está mi hija? ¿Qué habéis hecho con mi hija?... Jesús las miró con rostro severo e inmutable, indicó al ángel negro y dijo a las mujeres: «ID Y VED A DÓNDE HABÉIS MANDADO A VUESTRAS HIJAS»... Era un hermoso salón de baile, y había allí de sesenta a ochenta niñitas como de siete a doce años de edad que estaban bailando los bailes de última moda...todas las niñas estaban desnudas, y una inmensa víbora envolvía todo el cuerpo de cada una de ellas, y la cabeza se balanceaba del cuello de cada niña en medio del fuego... Él me dijo: «VUELVE Y DI A MI PUEBLO TODO ESTO». ${ }^{10}$

El infierno es presentado como un espacio en que los deseos son una tortura. Se pueden extraer muchas interpretaciones, pero la «visitante al infierno» destaca algunos aspectos como que las madres estaban «ricamente vestidas», «casi todas traían joyas». No solo está el peligro que se vayan al infierno las mujeres embellecidas, sino también las mujeres enriquecidas. La idea es resaltar la austeridad del cuerpo en relación con los bienes materiales. Luego, hay otro motivo de castigo: el baile. El mensaje es recomendar una vida ascética y frugal en todos los sentidos: somático, material y de vida. Las personas no deben de disfrutar de sus bienes, sino controlar sus pasiones. ¿Por qué? Uno de los motivos es para resaltar la igualdad al interior de la comunidad. Las mujeres jóve-

9 Revista Chile Pentecostal, mayo de 1924; Revista Fuego Pentecostés $\mathrm{N}^{\circ} 18,1929: 4$.

10 Revista Chile Pentecostal, mayo de 1924; Revista Fuego Pentecostés $\mathrm{N}^{\circ} 18,1929: 4$. 
nes pobres no deben seguir la forma de vestir de las adineradas, porque se van al infierno: un consuelo y una satisfacción diferidos.

\section{CONCLUSIONES}

El cuerpo en el pentecostalismo del segundo cuarto del siglo XX está afectado por los diferentes cambios sociales que en ese momento se daban, y la corporalidad femenina es el espacio de mayor disputa. Esta diputa tiene dos dimensiones: una estructural y otra subjetiva.

La dimensión estructural tiene que ver con los aspectos que influyen en la mujer, lo que viene desde fuera como imposición, control y vigilancia. Es la perspectiva de la que se han preocupado autores como Foucault. Desde esta dimensión, el cuerpo de la mujer aparece siempre como un territorio invadido y ocupado, explotado y oprimido, encerrado y vallado. Pero desde un estructuralismo constructivista está la postura de Bourdieu, donde aparecería la mujer como un sujeto condicionado, pero no determinado; por lo tanto, ella logar adecuarse, pero también innovar.

a) El pentecostalismo se presenta como protesta religiosa contra la modernización, pero también manifiesta propuestas simbólicas para transformar las necesidades en virtudes: el hambre en ayuno, la pobreza material en riqueza espiritual, los harapos y andrajos de ropas en realeza espiritual, casa habitación versus casa espiritual y el cuerpo físico versus cuerpo espiritual. En este sentido el pentecostalismo se sustenta en la ideología de una sociedad tradicional. Esta ideología implica a su vez un doble conflicto: rural-urbano y artesanal-industrial. i) El modelo religioso pentecostal hace referencia al cuerpo como tierra, casa, árbol o planta. La ropa es solo un aditamento artificial que permite entoldar frente a la hostilidad climática y embozarlo con decoro frente a los miramientos sociales. No obstante, esta concepción bucólica entra en conflicto con la concepción urbanizada del cuerpo: la idea de belleza dada y natural frente a otra adquirida y artificial. ii) Por otro lado, el pentecostalismo al sustentarse en una nostalgia del pasado artesanal y agrario, resignifica la pobreza. Por lo tanto, no había que avergonzarse de usar ropa de elaboración artesanal y casera y que, a su vez, como en todas las familias pobres, la ropa iba pasando de los hermanos mayores a los menores.

b) Le asigna decencia a la pobreza - algo que el catolicismo hace recién con el Concilio Vaticano Segundo-, pero además (algo que no hace el Concilio Católico) le asigna valores negativos a la riqueza como sinónimo de depravación moral y perdición salvífica. De esta 
manera el cuerpo y la belleza de la mujer joven pentecostal no deben seguir los cánones indicados por las revistas de modas, sino por los cánones bíblicos.

c) Se manifiesta una oposición abismante entre la sociedad y el pueblo. Mientras la oligarquía se autodenomina la sociedad, el pentecostalismo se autodefine como una comunidad (Willems, 1967; D’Epinay, 1968), aunque, al mismo tiempo, lanzó un crítica mordaz identificando «la sociedad con la suciedad». Según estos parámetros, la belleza física era un beneficio individual, mientras que la belleza espiritual era un beneficio comunitario.

d) Con relación al cuerpo, la mujer es la que más influye en las definiciones y reelaboraciones del cuerpo. La mujer no solo viste su cuerpo, también viste los otros cuerpos. Pero además ella es la productora de significados somáticos, así como reproductora y transmisora de valores somáticos.

e) Por último, las jóvenes no sólo implican transmisión/recepción, sino también son reproductoras y creadoras de cultura. En Chile ésta era una época en que ya se atisbaba la lucha generacional. Sin embargo, las distintas investigaciones sobre el pentecostalismo han invisibilizado el rol de los jóvenes que a pesar de los pentecostales, ya en los años de 1930 en adelante habían constituido grupos de jóvenes al interior de los templos.

La dimensión subjetiva. Como dijimos anteriormente, las investigaciones del pentecostalismo se hacen a espaldas del sujeto y se constituyen en un pentecostalismo sin pentecostales. También a los sujetos se les esconde en las categorías generales de género (mujer) o generación (juventud). Por otro lado, encontramos investigaciones vinculadas a las tradiciones funcionalista, marxista y durkheimiana en donde el pentecostalismo como religión solo constriñe, coacciona y enajena a la mujer. Sin embargo, creemos en la capacidad resistente, adaptativa y creativa del sujeto, en este caso la mujer, una productora biológica, pero también de la cultura.

En los distintos relatos encontramos conflictos que nacen fuera, pero que ya se encuentran en el cuerpo de la mujer por los procesos de socialización, y vemos cómo cada cosmovisión, instituciones o acontecimientos pretenden, luchan y debaten para imponer su definición sobre el cuerpo de la mujer. Sin embargo, la mujer joven no es una espectadora pasiva de las imposiciones, controles y vigilancia. La mujer es un sujeto, un actor (una actriz si se quiere) que observa las propuestas, las analiza y según sus intereses racionales y normativos las rechaza, acepta 
o toma solo aquello que no pone en peligro su vínculo comunitario. $\mathrm{O}$ bien si sus intereses están orientados hacia fuera de la comunidad, incorpora los valores somáticos que le ofrece la sociedad. Total, como la comunidad pentecostal se sustenta en valores familiares sabe que ella puede irse o alejarse de la comunidad y algún día volver como «hija pródiga» u «oveja descarriada» y la comunidad la aceptará. Aquella mujer joven cuyos intereses están orientados a la movilidad social al interior de la comunidad, como por ejemplo ser una líder religiosa, incorporará la propuesta comunitaria somática de una manera mucho más íntegra para alcanzar legitimidad y los requisitos simbólicos para su proyecto de vida. También están aquellas mujeres jóvenes que están en el umbral, que negocian, aunque tensional y conflictivamente, la incorporación de valores somáticos de la sociedad, incluso aquellos que la comunidad considera como transgresora. ${ }^{11}$

En la cultura pentecostal existe la visión de que los niños son obedientes y sumisos, aunque cueste mantenerlos tranquilos, pero quieren estar en el templo. Sin embargo, los jóvenes son definidos por su rebeldía, resistencia e indiferencia con las normas religiosas. Es la época cuando existe una tensión entre los «valores del mundo» y los «valores de Cristo». Es por ello que la cultura pentecostal no solo ha elaborado una dicotomía entre «salvados y perdidos», sino también entre los «consagrados» y los «descarriados». Son los que están, pero por su disconformidad y resistencia con las normas se van, aunque luego regresan. Ambos conversos perdidos y pródigos son lo que permiten las dinámicas y cambios religiosos. Es la idea de un proceso relacional: la comunidad cambia al individuo y el individuo transforma a la comunidad.

Por lo tanto, la mujer joven es una protagonista de su cuerpo. Ella es la que decide sobre su cuerpo, aunque sea en sí una libertad constreñida. Así la mujer joven hace de su cuerpo un espacio de integración, vinculación y transformación. La mujer joven es la que genera transformación sobre su cuerpo, constituyéndolo en un espacio de transformación social y cultural. Pero también ella no solo toma decisiones sobre su cuerpo, sino también es la que va tomando decisiones sobre otros cuerpos a partir de sus roles sociales y culturales como

11 Con relación al dilema estructura subjetividad en la teoría sociológica ver el artículo de Miriam Calvillo y Alejandro Favela Gavia «Hacia la categoría de sujeto social en la teoría sociológica». Revista Polis, Vol. 96, $\mathrm{N}^{\circ}$ 2. México: UAM. 
maestra, madre, tía, hermana, pastora, etc. Con todo, cuando adulta y autoridad ella también se constituye en vigilante y controladora de los cuerpos de otras mujeres jóvenes y vuelven a repetirse los conflictos, resistencias e innovaciones.

IQUiQue (CHILE), AGOSTO 2012

RECIBIDO: SEPTIEMBRE 2012

ACEPTADO: NOVIEMBRE 2012

\section{REFERENCIAS BIBLIOGRÁFICAS}

ANDRADE, Rosa (2008): «Manos que sanan. Experiencia de salud en mujeres pentecostales chilenas». Revista Cultura y Religión, Vol. 2, Nº3. Iquique: Universidad Arturo Prat.

ARAVENA, ANDREA y MANUEl BAEZA (2010): «Jóvenes chilenos y construcción socioimaginaria del ser-otro mujer». Última Década $\mathrm{N}^{\circ} 32$. Valparaíso: Ediciones CIDPA.

CARO, JoSÉ MARÍA (1942): Las sectas pentecostales. Santiago: Imprenta del Sagrado Corazón de Jesús.

CAROZZI, MARÍA (2002): «Cuerpo y conversión: explorando el lugar de los movimientos corporales estructurados y no habituales en las transformaciones de la identidad». Disponible en: www.naya.org.ar.

CAVAllieRI, Lina (1912): Revista Familia, Año III, N’27. Santiago: Zig-Zag.

CEPAL (1985): «Mujeres jóvenes en América Latina. Aportes para una discusión». Montevideo: Arca y Foro Juvenil.

D'EPINAY, CHRISTIAN (1968): El refugio de las masas: estudio sociológico del protestantismo chileno. Santiago: Editorial Pacífico.

ELIZALDE, SILVIA (2006): «El androcentrismo en los estudios de juventud: efectos ideológicos y aperturas posibles». Última Década $\mathrm{N}^{\circ} 25$. Valparaíso: Ediciones CIDPA.

FEDIAKOVA, EUGENIA (2011): «Juventud evangélica en Chile: ¿un nuevo modelo del evangelicalismo?». En MigUEL ÁNGEL MANSILLA y LUIS ORELLANA URTUBIA (editores): La religión en Chile del bicentenario. Católicos, protestantes, evangélicos, pentecostales y carismáticos. Concepción: Editorial CEEP.

Frodsham, Stanley (1946): With Signs Following. The Story of the Pentecostal Revival in the Twentieth Century. Springfield, Missouri: Gospel Publishing House.

GUZMÁN, NICOMEDES (1999): La sangre y la esperanza. Santiago: LOM.

HoOver, Willis (2008): Historia del avivamiento pentecostal en Chile. Concepción: Editorial CEEP. 
HuRTAdo, Alberto (1995): ¿Es Chile un país católico? Santiago: Editorial Los Andes.

HURTADO, JosEFINA (1993): «Mujer pentecostal y vida cotidiana». En Huellas. Seminario mujer y antropología. Santiago: CEDEM.

INJUV (2004a): Los jóvenes y las transformaciones culturales. Santiago: INJUV.

_ (2004b): Los y las jóvenes: similitudes y diferencias. Santiago: INJUV. (1997a): «Caracterización de las jóvenes beneficiarias del Programa Chile Joven y su inserción laboral». Santiago: INJUV.

_ (1997b): «Caracterización diagnóstica de la realidad de las mujeres jóvenes en Chile». Santiago: INJUV.

KesSLER, JuAn (1967): A Study of the Older Protestant Missions and Churches in Perú and Chile. With Special Reference to the Problems of Division, Nationalism and Native Ministry. Goes: Oosterbaan \& le Cointre N. V.

MADURO, OtTO (2007): «Notas sobre pentecostalismo y poder entre inmigrantes latinoamericanos en la ciudad de Newark (New Jersey, EUA)». Horizontes Antropológicos, Año 13, $\mathrm{N}^{\circ} 27$. Porto Alegre.

MANSILLA, Miguel ÁNGEL y LUIS LLANOS (2010): «La generación P: las representaciones de los jóvenes en el pentecostalismo chileno en la primera mitad del siglo XX». Última Década $\mathrm{N}^{\circ} 33$. Valparaíso: Ediciones CIDPA.

MENA, IGNACIO (2008): «El ascetismo pentecostal gitano y la gestión corporal. Una aproximación desde la antropología del cuerpo». Revista Atenea $\mathrm{N}^{\circ} 13$. Barcelona: Universidad Autónoma de Barcelona.

- (2007): «La fe en el cuerpo. La construcción biocorporal en el pentecostalismo gitano». Revista de Antropología Experimental N N7. Jaén: Universidad de Jaén.

MonTECINO, SONIA (2002): «Caminar con el espíritu: perspectivas de género en el movimiento evangélico pentecostal». Estudios Públicos $\mathrm{N}^{\circ} 87$. Santiago: CEP.

MOSQUIERA, MARIELA (2012): «Revolución de santidad: género, sexualidad y juventud en comunidades evangélico-pentecostales de Buenos Aires». XXX Congress of the Latin American Studies Association, San Francisco, California.

(2010): «La política requiere de leones, no de ovejas: participación política en jóvenes cristiano-evangélicos». Revista RITA, $\mathrm{N}^{\circ} 4$. Disponible en: www.revue-rita.com.

MOULIAN, RODRIGO (2009): «Somatosemiosis e identidad carismática pentecostal». Revista Cultura y Religión, Vol. 3, №2. Iquique: Universidad Arturo Prat.

ORELLANA, ZICRI (2010): Mujeres pentecostales: construcción del género a través de la experiencia religiosa. Tomé: Editorial al Aire Libre. (2009): «La iglesia pentecostal: comunidad de mujeres». Revista Cultura y Religión, Vol. 3, №2. Iquique: Universidad Arturo Prat. 
OYARZÚN, ÁSTRID (2001): «Políticas publicas y mujer joven: entre la madre y la hija». Última Década N²5. Valparaíso: Ediciones CIDPA.

PEREA, SABINO (1998)): «Anna Perenna: religión y ejemplaridad mítica». En Espacio, tiempo y forma. Serie II, historia antigua. Tomo 11.

PORTOCARRERO, GONZALO (1999): «Los discursos de género en la juventud peruana y la experiencia comunicativa de andamios». La Ventana $\mathrm{N}^{\circ} 10$. Lima.

RIQUER, FlORINDA y ANA MARÍA TEPICHÍN (2001): «Mujeres jóvenes en México. De la casa a la escuela, del trabajo a los quehaceres del hogar». En E. PIECK (coordinador): Los jóvenes y el trabajo. México: UIA-IMJUUNICEF-CONALEP-OIT-CINTEFOR.

SEMAN, PABLO (1994): «Identidad de los jóvenes pentecostales». En ALEJANDRO FRIGERIO (compilador): Pentecostalismo en la Argentina. Vol. 1. Buenos Aires.

SLOOTWEG, HANNE (1989): Mujeres pentecostales en Chile: un caso en Iquique. Iquique: TER.

VÁSQUEZ, L. (2007): «Modernidad y crisis de sentido entre los jóvenes evangélicos. El caso de la agrupación Impacto Juvenil». En Más allá del espíritu, acciones y prácticas en iglesias pentecostales. México: CIESAS/Colegio de Michoacán.

Willems, EMILIO (1967): Followers of the New Faith: Culture Change and the Rise of Protestantism in Brazil and Chile. Nashville, Tennessee: Vanderbilt University Press. 